\title{
Psychological Intervention Measures for Mental Health During COVID-19 Pandemic
}

\author{
Ancha Rani ${ }^{1}$, Vandana Singh Malik ${ }^{2}$ and Rakesh Kumar Behmani ${ }^{3}$ \\ ${ }^{1,2}$ Research Scholar, ${ }^{3}$ Professor \\ ${ }^{1,2,3}$ Department of Applied Psychology, Guru Jambheshwar University of Science and \\ Technology, Hissar, Haryana, India.
}

\begin{abstract}
The COVID-19 pandemic is a global health problem affecting around 213 countries and territories worldwide, with more than 6,474,200 cases reported and 382,914 deaths documented so far. The World Health Organization announced COVID-19 is a pandemic outbreak on 11 March, 2020. We are facing a medical emergency because of COVID-19 pandemic. These large incidents have negative and detrimental effects on mental health and well-being of individuals worldwide. Widespread infectious disease outbreaks such as COVID-19 are linked to mental illness symptoms and psychological distress. Preliminary studies indicate that depression (28\%) and anxiety (16\%) symptoms and self-reported stress (8\%) are typical psychological responses to the COVID-19 pandemic, which could be correlated with sleep disturbance. The physical and psychological wellbeing of general people, particularly health care practitioners, has been profoundly affected by illness. The main objective of this review-based study is to focus mental health and psychological interventions which can be provided during this pandemic. Stress, fear, anxiety, panic, frustration is very common during COVID-19 pandemic and these can be reduced by some psychological intervention measures.
\end{abstract}

Keywords: COVID-19, Mental Health, Psychological Intervention.

\section{INTRODUCTION}

\section{Background}

The World Health Organization announced coronavirus 2019 (COVID-19) outbreak a public health emergency on $30^{\text {th }}$ January 2020, when COVID-19 cases surpass the Severe Acute Respiratory Syndrome (SARS) cases of 2003. It spread exponentially across the world. During COVID-19 epidemic, a study was carried out which revealed that $53.8 \%$ of respondents 
evaluated the psychological effect as moderate or severe. Depressive symptoms were reported in $16.5 \%$, anxiety in $28.8 \%$, and stress found in $8.1 \%$.

\section{Mental Health}

According to World Health Organization (1948) "Mental health is a state of well-being in which an individual realizes his or her own abilities, can cope with the normal stresses of life, can work productively, and is able to make a contribution to his or her community."

\section{Psychological Interventions}

Psychological intervention is a way to provide support to individuals for their well-being and to enhance their efficiency, self-worth. It helps in boosting confidence of individual.

\section{REVIEW OF LITERATURE}

\section{Mental Health and COVID-19}

During this epidemic, people are who are infected, their caregivers, health professionals, police personnel's and general population across the world are going through emergency condition and feel anxiety, depression in lockdown, isolation and in quarantine period. Mental health is not given priority as much importance is given to physical health, but past researches revealed that mental health and public heath have strong interdependent relationship. Psychological anxiety is maybe progressively more intense now contrasted with 17 year back during the SARS time frame, with expanded air travel and improved worldwide communication rendering the transmission of pandemic considerably easier. Extensive media reporting of COVID-19 is going on, it affects physical and psychological reaction of public to this epidemic threat, which may intensify anxiety despite working as an essential medium for promoting preventive measures for infection. Past studies have uncovered a significant and extensive range of mental effect that epidemic can incur on human. It can hasten new psychological symptoms in a individual without any particular mental disorder. It can also aggravate the condition of someone who already suffering from mental disorders and it may lead anxiety in care-giver of infected person.

Notwithstanding direct exposure, individual may encounter anxiety or fear of getting ill or death, vulnerability, or put blame on those who are sick, may face psychological breakdown. 
Psychiatric morbidities significantly fluctuate from panic attack, anxiety, depression, physical symptoms, and posttraumatic stress disorder (PTSD) to psychosis and may even lead to suicidal tendency, particularly, in young age person or expanded self blame person. Studies have shown that individuals who are quarantined for a long period encounter with psychological distress and also have chances for increased risk of posttraumatic stress disorder symptoms that are coupled with depression. Studies conducted on survivor of other virus caused health emergency, for example SARS, revealed that high rate of prevalence of depression and PTSD have been reported( Hawryluck, et al., 2004; Liu et al.,2016; Carmassi et al., 2017; Carmassi et al., 2018; Di Giuseppe et al., 2020).

\section{Psychological Interventions}

Psychological intervention helps in boosting confidence of individual. During this COVID-19, psychological support is provided by various institution and universities through online counsellling, by using various platforms of social media, or e-mails. This is the easiest way to communicate with the people and to disseminate awareness for mental health and well being of individual. Psychological associations of various nations shared recommendations to handle mental health issues face by people during COVID-19 emergency. The purpose of these guidelines is to provide motivation for coping emotional challenges people encounter during lockdown, quarantine and isolation period. Psychological interventions are required for people who are suffering with COVID-19 and particularly, health professionals who are dealing with this emergency. Psychopathological changes lead to maladaptive behaviours and various emotional disorders. Mental health issues like anxiety, fear, depression is worse for their own mental health of health service provider, and as they modulate treatment for all. Chinese authorities prepared online questionnaires for knowing mental health status of people, the purpose of these measures is to provide direction in resource allocation and for improving patient tailored treatment. It is important to take action to for dealing with psychological response to COVID-19. During the early long stretches of the flare-up of COVID-19 it is important to enact psychological support framework for health care professionals and open on the web correspondence pathways by using smart gadgets to make mental help accessible to them. 
People generally not discuss about their mental health and well-being and not reveal their psychological conditions. Online mode for psychological support is the convenient and easiest ways which help psychologist to address masses in just one go.

This table depicted various stages and what interventions can be provided to individuals:-

\begin{tabular}{|c|c|c|}
\hline STAGES & PROFFESSIONALS & INTERVENTIONS \\
\hline 1 & $\begin{array}{l}\text { Psychologist and } \\
\text { Health care professionals }\end{array}$ & $\begin{array}{l}\text { - Psycho education and support should be } \\
\text { provided to heath care professionals. } \\
\text { - Construction and administration of } \\
\text { online questionnaires. }\end{array}$ \\
\hline 2 & Psychologists and Psychiatrists & $\begin{array}{l}\text { Psychological support provided through } \\
\text { open online mode. }\end{array}$ \\
\hline 3 & Psychologist and Police & $\begin{array}{l}\text { - Production and distribution of psycho } \\
\text { educational informational content for } \\
\text { people. } \\
\text { - Toll-free numbers should be } \\
\text { disseminated for victims who are going } \\
\text { through domestic violence. }\end{array}$ \\
\hline 4 & Psychologist and Psychotherapists & $\begin{array}{l}\text { - Design and provide interventions for } \\
\text { management of PTSD, depression and } \\
\text { substance abuse. }\end{array}$ \\
\hline
\end{tabular}

Source: Orrù, G., Ciacchini, R., Gemignani, A., \& Conversano, C. (2020). Psychological intervention measures during the COVID-19 pandemic. Clinical Neuropsychiatry, 17(2), 76-79.

Intervention provided should focus on management and containment of health service provider, infected people and their care giver's behavior. Psychologist and psychotherapist should prepare questionnaires that can easily accessible by people and that can help to rule out negative effect and psychological risk factors of individual. These interventions also help to find out need of general population.

In this innovative period and in the midst of epidemic attack, various online mode or video conferencing channels like Zoom are used to provide web psychotherapy to patients suffering with mental disorder. It helps to mitigate transmission of infection from face-to-face therapy. It is 
easy and efficient way to meet demand of nation in this epidemic. It is advantageous to give about web or Smartphone psycho education about epidemic; it helps in boosting mental wellness and to start psychological intervention at just one click. Patients and general population vulnerable to mental disorders, for them cognitive therapy provided by psychotherapist may help them to mitigate anxiety, depression, PTSD, and other psychological illness by challenging their cognitive bias. Mindfulness based therapy focused on various mindfulness meditation techniques which help individual to be in present moment or non-judgmentally to be aware of present moment, it helps to alleviate stress in people with physical conditions.

\section{CONCLUSION}

Due to risk infection, clinical psychiatrist, psychiatrist and mental health workers are not allowed to enter in isolation ward of patients and they are also discouraged generally, online frontline health-care workers are main personnel who can provide psychological support to people who are infected and who are quarantined. But technology has become advanced so mental health professionals can play a crucial role in enhancing mental health and well-being of general population. Psychological support and psychotherapies are boon for individuals who are going through mental illness.

\section{REFERENCES}

Brooks, S. K., Webster, R. K., Smith, L. E., Woodland, L.,Wessely, S., Greenberg, N., \& Rubin, G. J. (2020). The psychological impact of quarantine and how to reduce it: rapid review of the evidence. The Lancet. DOI: 10.1016/S0140-6736(20)30460-8

Carleton, R. N., Mulvogue, M. K., Thibodeau, M. A.,McCabe, R. E., Antony, M. M., \& Asmundson,G.(2012).Increasinglycertain about uncertainty: Intolerance of uncertainty across anxiety and depression. Journal of anxiety disorders, 26(3), 468-479. DOI: 10.1016/j. janxdis.2012.01.011

Carmassi, C., Bertelloni, C. A., Gesi, C., Conversano, C., Stratta, P., Massimetti, G., \& Dell'Osso, L. (2017). New DSM-5 PTSD guilt and shame symptoms among Italian 
earthquake survivors: Impact on maladaptive behaviors.Psychiatry research,251, 142147. DOI: 10.1016/j.psychres.2016.11.026

Carmassi, C., Gesi, C., Corsi, M., Cremone, I. M., Bertelloni, C. A., Massimetti, E., ... \& Dell'Osso, L. (2018). Exploring PTSD in emergency operators of a major University Hospital in Italy: a preliminary report on the role of gender, age, and education.

Annals of general psychiatry, 17(1), 17. DOI: 10.1186/s12991-018-0184-4

Carmassi, C., Gesi, C., Simoncini, M., Favilla, L., Massimetti, G., Olivieri, M. C., ... \& Dell'Osso, L. (2016). DSM- 5 PTSD and posttraumatic stress spectrum in Italian emergency personnel: correlations with work and social adjustment. Neuropsychiatric disease and treatment, 12, 375. DOI: 10.2147/NDT.S97171

Conversano, C. (2019). Psychological common factors in chronic diseases. Frontiers in Psychology, 10, 2727. DOI:Defensive responses to stressful life events associated with cancer diagnosis. Mediterranean Journal of Clinical Psychology, 8(1). DOI: $10.6092 / 2282-1619 / \mathrm{mjcp}-2384$

Di Giuseppe, M., Miniati, M., Miccoli, M., Ciacchini, R., Orrù, G., Lo Sterzo, R., Di Silvestre, A., Conversano, C. (2020). DSM-5 PTSD guilt and shame symptoms among Italianearthquake survivors: Impact on maladaptive behaviors.Psychiatry research, 251, 142-147. DOI: 10.1016/j.psychres.2016.11.026

Duan, C., Linder, H., \& Huremović, D. (2019). Societal, Public, and [Emotional] Epidemiological Aspects of a Pandemic.In Psychiatry of Pandemics (pp. 45-53). Springer, Cham. DOI: 10.1007/978-3-030-15346-5_4

Duan, L., \& Zhu, G. (2020). Psychological interventions for people affected by the COVID-19 epidemic. The Lancet Psychiatry. DOI: 10.1016/S2215-0366(20)30073-0

Hall RCW, Hall RCW, Chapman MJ. The 1995 Kikwit Ebola outbreak: lessons hospitals and 
physicians can apply to future viral epidemics. Gen Hosp Psychiatry 2008;30:446-52.

Hawryluck, L., Gold, W. L., Robinson, S., Pogorski, S., Galea, S., \& Styra, R. (2004). SARS control and psychological effects of quarantine, Toronto, Canada. Emerging Infectious Diseases, 10(7), 1206. DOI: 10.3201/eid1007.030703

Ho, C. S., Chee, C. Y., \& Ho, R. C. (2020). Mental Health Strategies to Combat the Psychological Impact of COVID-19 Beyond Paranoia and Panic. Annals of the Academy of Medicine, Singapore, 49 (1), 1

Huremović, D. (2019). Preparing for the Outbreak. In Psychiatry of Pandemics (pp. 65-76). Springer, Cham.DOI: 10.1007/978-3-030-15346-5_6

Iasevoli, M., Giantin, V., Voci, A., Valentini, E., Zurlo, A., Maggi, S., ... \& Manzato, E. (2012). Discussing end-of-life care issues with terminally ill patients and their relatives: comparisons among physicians, nurses and psychologists. Aging clinical and experimental research, 24(3 Suppl), 35-42

Lee, S., Chan, L. Y., Chau, A. M., Kwok, K. P., \& Kleinman, A. (2005). The experience of SARS-related stigma at Amoy Gardens. Social science \& medicine, 61(9), 2038-2046. DOI: 10.1016/j.socscimed.2005.04.010

Liu, S., Yang, L., Zhang, C., Xiang, Y. T., Liu, Z., Hu, S., \& Zhang, B. (2020). Online mental health services in China during the COVID-19 outbreak. The Lancet Psychiatry. DOI: 10.1016/S2215-0366(20)30077-8

Martino, G., Langher, V., Cazzato, V., \& Vicario, C. M. (2019). Psychological factors as determinants of medical conditions. Frontiers in psychology, 10, 2502. DOI: 10.3389/fpsyg.2019.02502

McEwen, B. S. (1999). Stress and hippocampal plasticity. Annual review of neuroscience, 22(1), 105-122. DOI: 10.1146/annurev.neuro.22.1.105 
Müller N. Infectious diseases and mental health. In: Sartorius N, Holt RIG, Maj M, editors. Key Issues in Mental Health. Basel: S. KARGER AG; 2014. p. 99-113. Available at: https://www.karger.com/Article/ FullText/365542. Accessed on 8 March 2020. NEJMp0911047

Orrù, G., Ciacchini, R., Gemignani, A., \& Conversano, C. (2020). Psychological intervention measures during the COVID-19 pandemic. Clinical Neuropsychiatry, 17(2), 76-79.

Ofri D. (2009). The emotional epidemiology of H1N1 influenza vaccination. $N$ Engl J Med., 36(27): 2594-5. DOI: 10.1056/ NEJMp0911047

Pawluk, E. J., \& Koerner, N. (2013). A preliminary investigation of impulsivity in generalized anxiety disorder. Personality and Individual Differences, 54(6), 732-737. DOI: 10.1016/j. paid.2012.11.027

PTSD in emergency operators of a major UniversityHospital in Italy: a preliminary report on the role of gender, age, and education. Annals of general psychiatry, 17(1), 17. DOI: 10.1186/s12991-018-0184-4

Qiu, J., Shen, B., Zhao, M., Wang, Z., Xie, B., \& Xu, Y. (2020). A nationwide survey of psychological distress among Chinese people in the COVID-19 epidemic: implications and policy recommendations. General Psychiatry, 33(2). DOI : 10.1136/gpsych-2020100213

Robertson, E., Hershenfield, K., Grace, S. L., \& Stewart, D. E. (2004). The psychosocial effects of being quarantined following exposure to SARS: a qualitative study of Toronto health care workers. The Canadian Journal of Psychiatry, 49(6), 403-407. DOI: 10.1177/070674370404900612

Rodin P, Ghersetti M, Odén T. Disentangling rhetorical subarenas of public health crisis communication: a study of the 2014-2015 Ebola outbreak in the news media and social media in Sweden. J Contingencies Crisis Manag 2018;27:237-46. 
Sim K, Huak Chan Y, Chong PN, Chua HC, Wen Soon S. Psychosocial and coping responses within the community health care setting towards a national outbreak of an infectious disease. J Psychosom Res 2010;68:195-202.

Tang L, Bie B, Park SE, Zhi D. Social media and outbreaks of emerging infectious diseases: a systematic review of literature. Am J Infect Control 2018;46:962-72.

Tucci V, Moukaddam N, Meadows J, Shah S, Galwankar SC, Kapur GB. The forgotten plague: psychiatric manifestations of Ebola, Zika, and emerging infectious diseases. J Glob Infect Dis 2017;9:151-6.

Wang C, Pan R, Wan X, Tan Y, Xu L, Ho CS, et al. Immediate psychological responses and associated factors during the initial stage of the 2019 coronavirus disease (COVID-19) epidemic among the general population in China. Int J Environ Res Public Health 2020;17:1729. 